Technical Note

\title{
A Computer Color-Matching Study of Reverse Micellar Dyeing of Wool with Reactive Dyes
}

\author{
Yanming Wang ${ }^{1}$, Yiu-lun Tang ${ }^{1}\left(\mathbb{D}\right.$, Cheng-hao Lee ${ }^{2} \mathbb{D}$ and Chi-Wai Kan ${ }^{1, *}$ \\ 1 Institute of Textiles and Clothing, The Hong Kong Polytechnic University, Hung Hom, Kowloon, \\ Hong Kong, China; tcymwang@polyu.edu.hk (Y.W.); alan.yl.tang@connect.polyu.hk (Y.-1.T.) \\ 2 Department of Applied Biology and Chemical Technology, The Hong Kong Polytechnic University, \\ Hung Hom, Kowloon, Hong Kong, China; bcchlee@polyu.edu.hk \\ * Correspondence: tccwk@polyu.edu.hk; Tel.: +852-2766-6531
}

Received: 21 December 2018; Accepted: 9 January 2019; Published: 14 January 2019

\begin{abstract}
Computer color-matching (CCM) and the levelness of poly(ethylene glycol)-based reverse-micellar dyed wool fabrics in octane and nonane were investigated and compared with a conventional water-based dyeing system. Reflectance curves and calibration curves exhibited no chromatic change and maintained high linearity in both dyeing systems. The linearity of water-dyed calibration curves was slightly higher than that of the reverse-micellar dyed curves. The color yield, in term of $\mathrm{K} / \mathrm{S}_{\text {sum }}$ values, of solvent-dyed samples was found to be generally higher than that of water-based dyed samples at various calibrated dye concentrations. The concentrations predicted by $\mathrm{CCM}$ were close to the theoretical concentrations for both dyeing methods. This indicates that octaneand nonane-assisted reverse-micellar dyeing of wool is able to generate color recipes comparable to the conventional water-based dyeing system. The solvent-dyed samples, measured by the relative unlevelness indices (RUI), exhibit good-to-excellent levelness, which is highly comparable with the water-dyed samples.
\end{abstract}

Keywords: wool fiber; non-ionic surfactant; octane; nonane; reverse micelle; reactive dye; color-matching; levelness

\section{Introduction}

Wool, with distinct characteristics of soft handle, good warmth retention, high moisture regain, and high ignition temperature, is an important natural animal protein fiber that helps human beings live an eco-friendly lifestyle [1,2]. Wool is an important fiber in the textile industry; however, due to the presence of a high number of disulfide cysteine cross-linkages (-S-S-), it has hydrophobicity on its surface $[3,4]$ and, thus, problems of wettability and dyeability.

In the conventional water-based dyeing procedure, textile reactive dyes are widely used for coloration of wool fiber owing to their excellent fastness properties. Unlike the reactive coloration of cotton, the fixation of dye on wool fiber is achieved via an increase in temperature under weak acidic conditions ( $\mathrm{pH} 4-6$ ), instead of the addition of alkali, which may cause fiber degradation [5]. The dye-fiber interaction is relevant to the chemical bonding between water-soluble groups of the dyes and the amino and hydroxyl groups of wool fiber, improving the fixation rate and colorfastness [6]. However, the fixation of reactive dyes on wool is insufficient to achieve good wet-fastness properties since fixation via Coulombic interaction is unavoidable, and additional alkali after-treatment is required for neutralization $[7,8]$. In addition, the use of reactive dyes in the conventional water-based dyeing approach reveals some drawbacks, such as low dye fixation, requirement of a huge amount of dyeing auxiliaries, and high volume of effluent discharge [9]. These problems adversely affect the environment, 
as well as the quality of life of human beings, animals, and aquatic living beings, and it is contradictory to stringent environmental regulations.

To reduce wastewater discharges and environmental impacts, various methods were used to improve the exhaustion and fixation of dyes on wool fiber. These attempts included (a) pretreatment or modification of wool fiber before coloration [10-16]; (b) synthesis of novel dyestuffs [8,17]; (c) microencapsulation with liposomes [18,19]; (d) reuse of dyebath [20] and seawater [21]; (e) foam dyeing [22]; (g) ultrasound-assisted dyeing [23-25]; and (h) solvent-assisted dyeing using mixed solvent [26], supercritical critical fluid, and/or reverse micelle [27-32].

Reverse micelles are self-assembled colloidal structures formed by non-ionic surfactants in organic solvent with nanoscale water pools in hydrophilic cores [33]. Previous literature on the colorimetric measurement of textiles was achieved using spectrophotometry [34-38]. In our previous studies, we successfully used poly(ethylene glycol) (PEG)-based non-ionic surfactants to facilitate the formation of reverse micelles, the analysis of stability and dispersity of well-defined reverse micelles with different reverse-micellar dyeing parameters, and the application of the computer color-matching (CCM) technique to study the dyeing properties of cotton fiber in different non-aqueous solvent media [39-44]. As the aesthetic appearance of most textile products is a mixture of colors rather than a single color, $\mathrm{CCM}$ is an important aspect that cannot be neglected in industrial dyeing applications $[45,46]$. However, to the best of our knowledge, most researchers focused on dyeing of wool with a single color, while the feasibility of CCM's application on wool fiber is still unknown and is yet to be reported in the literature.

The main aims of this study included (a) construction of calibration curves for reactive dyes in conventional aqueous and alkane non-aqueous dyeing media; (b) simulated dyeing of wool fabrics with known dye concentration for both dyeing approaches; (c) measurement of the reflectance, K/Ssum, CIE L*a* $b^{*}$ values, and levelness of the dyed wool samples; (d) prediction of the color recipe between batch samples and standard samples using computer color-matching (CCM); and (e) assessment of the difference between computer color-matching and levelness of conventional water-dyed samples and alkane-dyed samples.

\section{Materials and Methods}

\subsection{Materials and Reagents}

Woven wool plain fabrics (73 warps per inch $\times 60$ wefts per inch) were firstly immersed in acetone (GR grade, Duksan, Gyunggido, Korea) for $5 \mathrm{~min}$ and then rinsed with $2 \mathrm{~g} / \mathrm{L}$ soap. After soaping, the fabrics were washed in cold water and then air-dried at room temperature. The air-dried fabrics were then conditioned for at least $24 \mathrm{~h}$ at $20 \pm 2{ }^{\circ} \mathrm{C}$ and relative humidity of $65 \pm 2 \%$ prior to further experiment. The non-ionic surfactant, poly(ethylene glycol) (12) tridecylether $\left(\mathrm{C}_{13} \mathrm{H}_{27}\left(\mathrm{OCH}_{2} \mathrm{CH}_{2}\right)_{12} \mathrm{OH}\right)$ was used (reagent grade, Sigma Aldrich, St. Louis, MO, USA). Octane and nonane (reagent grade, ACROS, Fair Lawn, NJ, USA) were used as the dyeing media and $n$-octanol (reagent grade, Alfa Aesar, Heysham, UK) was used as a co-surfactant in the dyeing process. Acetic acid (reagent grade, Sigma Aldrich, St. Louis, MO, USA) and sodium sulfate (reagent grade, Sigma Aldrich, St. Louis, MO, USA) were used in conventional aqueous dyeing. Realan reactive dyes (Realan Red EHF, Realan Yellow EHF, and Realan Blue EHF, Dystar, Shanghai, China) were used directly without further purification.

\subsection{Preparation of Calibration Curvex}

Wool woven fabrics were used. Calibrated dyeing of reverse-micellar dyeing and conventional aqueous dyeing (dye concentrations of $0.1 \%, 0.5 \%, 1.5 \%, 2.5 \%$, and $3.5 \%$ of weight of wool fiber (owf)) was conducted with dyeing parameters shown in Tables 1 and 2, respectively. Figures 1 and 2 show the dyeing profiles of the conventional aqueous dyeing approach and the alkane reverse-micellar dyeing approach, respectively. The dyed samples used for the preparation of calibration curves were named as batch samples. 
Table 1. Dyeing parameters for octane and nonane.

\begin{tabular}{cc}
\hline Parameter & Value \\
\hline Wool-to-solvent weight ratio $(w / v)$ & $1: 10$ \\
Surfactant-to-co-surfactant molar ratio & $1: 8$ \\
Surfactant-to-water molar ratio & $0.04: 1$ \\
Water-pool volume for dye $(\mathrm{mL})$ & 0.5 \\
Dyeing time $(\mathrm{min})$ & 50 \\
Dyeing temperature $\left({ }^{\circ} \mathrm{C}\right)$ & 88 \\
\hline
\end{tabular}

Table 2. The concentration of $\mathrm{Na}_{2} \mathrm{SO}_{4}$ and $\mathrm{pH}$ at various weight percentages of reactive dye for conventional water dyeing.

\begin{tabular}{ccccccc}
\hline \multicolumn{1}{c}{ Liquid Ratio $\mathbf{5 0 : 1 , 9 8}{ }^{\circ} \mathbf{C}$} \\
\%ye of weight of wool fiber $(\%$ owf $)$ & 0.1 & 0.5 & 1.5 & 2.5 & 3.5 \\
Salt $\left(\mathrm{Na}_{2} \mathrm{SO}_{4}\right)$ & $\mathrm{g} / \mathrm{L}$ & 2 & 2 & 2 & 2 & 2 \\
$\mathrm{pH}$ & & 5 & 4.5 & 4.2 & 4 & 3.8 \\
\hline
\end{tabular}

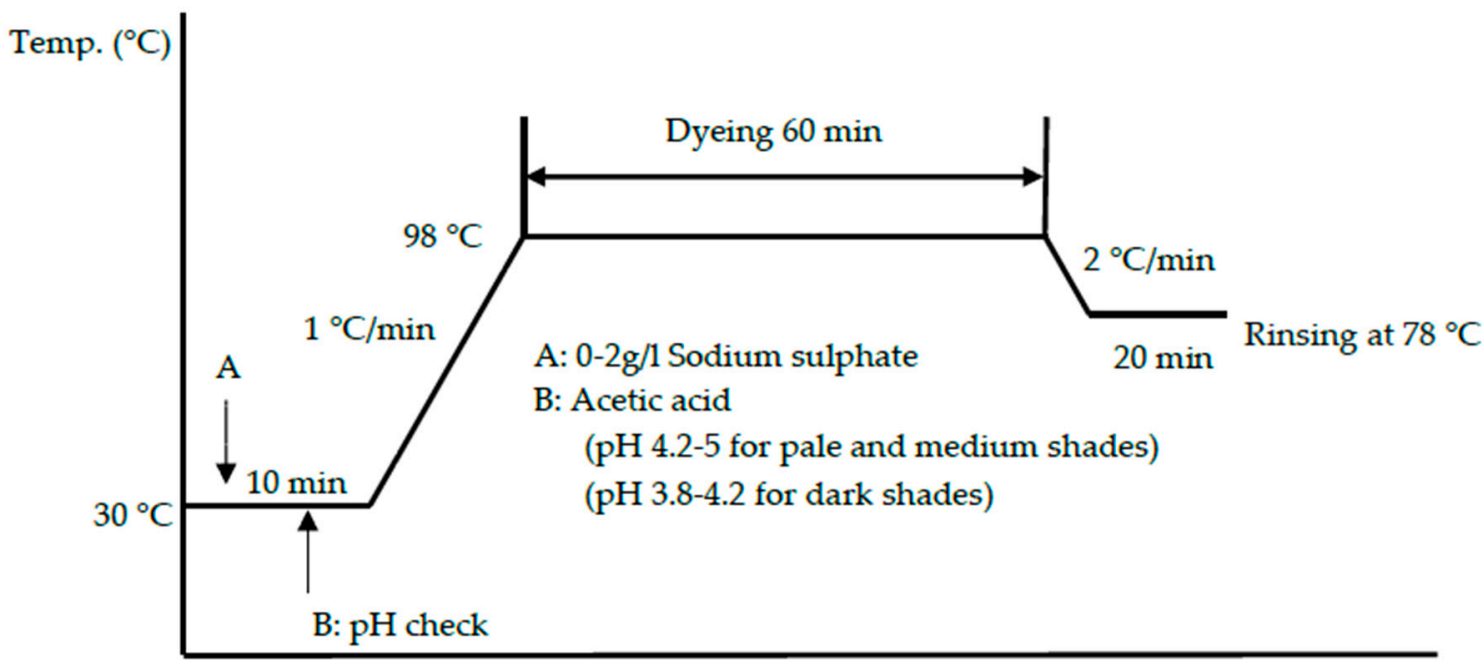

Figure 1. Profile of the conventional dyeing approach with salt.

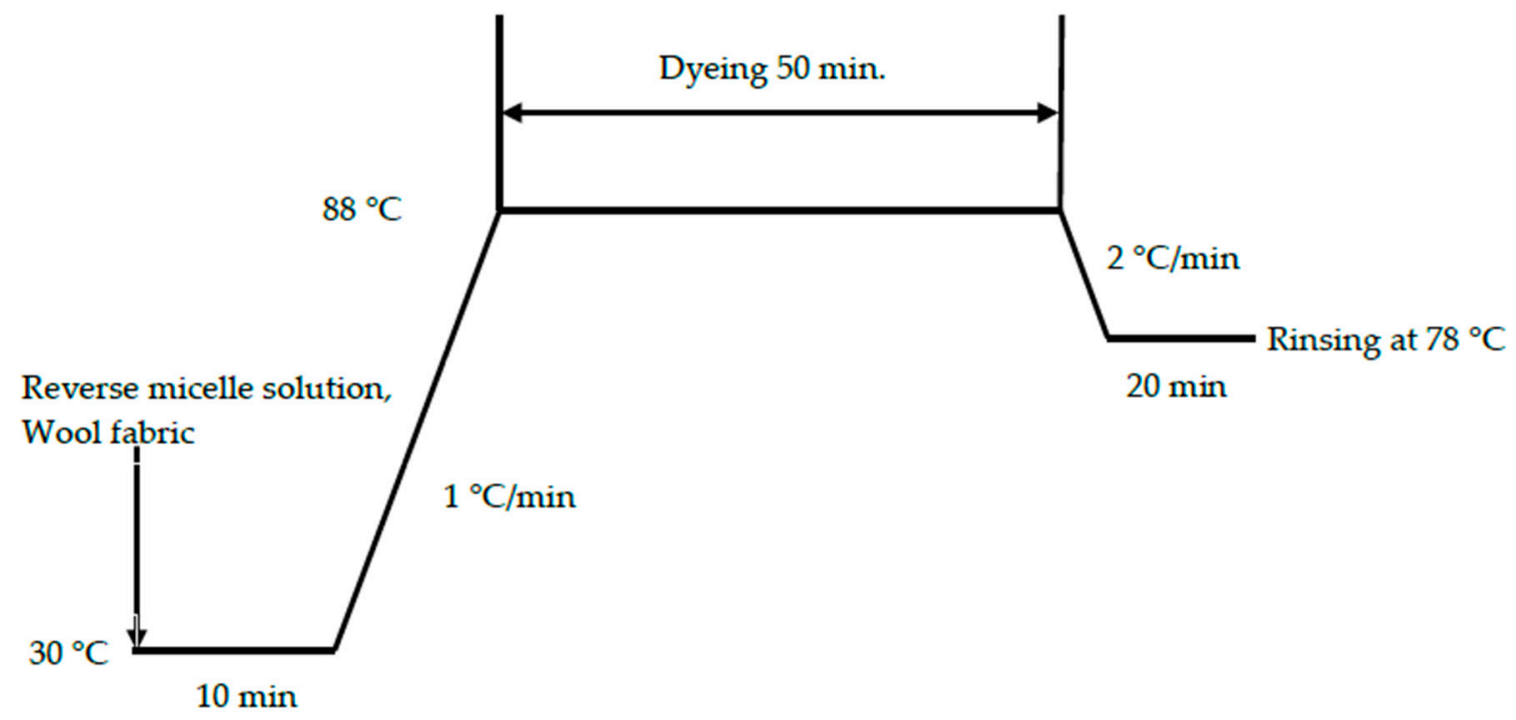

Figure 2. Profile of the reverse-micelle dyeing approach in octane and nonane without salt. 


\subsection{Simulated Dyeing}

Simulated dyeing using known concentrations of dye was launched to predict the dye concentrations of calibrated conventional water-based and reverse-micellar methods. The dyed woven wool fabrics were used for color-matching and these samples were named as standard samples. Table 3 shows the concentrations of dye used for the preparation of color mixtures.

Table 3. Dye concentrations (\%) for preparing color mixtures.

\begin{tabular}{ccccc}
\hline Solvent & Standard Sample & Red (\%) & Yellow (\%) & Blue (\%) \\
\hline \multirow{2}{*}{ Water } & Sample 1 & 0.100 & 0.100 & 0.100 \\
& Sample 2 & 0.500 & 0.500 & 0.500 \\
& Sample 3 & 1.000 & 1.000 & 1.000 \\
\hline \multirow{2}{*}{ Octane } & Sample 4 & 0.100 & 0.100 & 0.100 \\
& Sample 5 & 0.500 & 0.500 & 0.500 \\
& Sample 6 & 1.000 & 1.000 & 1.000 \\
\hline \multirow{2}{*}{ Nonane } & Sample 7 & 0.100 & 0.100 & 0.100 \\
& Sample 8 & 0.500 & 0.500 & 0.500 \\
& Sample 9 & 1.000 & 1.000 & 1.000 \\
\hline
\end{tabular}

\subsection{Plot of Calibration Curves}

A spectrophotometer (Color Eye 7000A, X-Rite, Grand Rapids, MI, USA) was used for measuring the color yield of the dyed samples. The $\mathrm{K} / \mathrm{S}_{\text {sum }}$ value was obtained by summation of $\mathrm{K} / \mathrm{S}$ values within 400-700-nm wavelength range. The condition of measurement on the dyed fabric surface was specular reflection under a large aperture with a diameter of $30 \mathrm{~mm}$. A $10^{\circ}$ observer angle and a $\mathrm{D}_{65}$ light source were used. Dyed samples were folded to ensure opacity. Graphical plots (calibration curves) of $\mathrm{K} / \mathrm{S}_{\text {sum }}$ value versus concentration of dye (\%) were then prepared.

The color yield, $\mathrm{K} / \mathrm{S}$ value, was calculated from Equation (1) at wavelengths ranging from 400 to $700 \mathrm{~nm}$ in steps of $10 \mathrm{~nm}$. As the K/S value increases, the dye uptake and color yield improve.

$$
\mathrm{K} / \mathrm{S}=(1-\mathrm{R})^{2} / 2 \mathrm{R},
$$

where $\mathrm{K}$ is the absorption coefficient, depending on the colorant concentration, $\mathrm{S}$ is the scattering coefficient, caused by the dyed substrate, and $\mathrm{R}$ is the reflectance factor of the colored sample at a specific wavelength [39].

\subsection{Dye Recipe Prediction}

Nine color difference equations, including CIE L*a* $b^{*}, C I E L^{*} u^{*} v^{*}, A N L A B$, Hunter lab, FMC2, JPC 79, CMC 1.0, BFD 1.0, and CIE94 1.0, were used to predict the dye recipe. Color yields of samples dyed with different concentrations of dye were measured with apparatus and conditions similar to those mentioned in Section 2.4.

\subsection{The CIE $L^{*} a^{*} b^{*}$ Value Measurement}

CIE L*a* $b^{*}$ values of the dyed fabrics were measured with similar apparatus and conditions as those mentioned in Section 2.4. 


\subsection{Levelness Measurement}

Relative unlevelness indices (RUI), an indicator of levelness of the dyed samples, were obtained by calculating the reflectance values of three randomly selected locations of standard and batch samples with the use of Equations (2)-(5) [47]. The interpretation of the value of RUI is as listed in Table 4.

$$
\begin{gathered}
\mathrm{s}_{\lambda}=\sqrt{\frac{\sum_{\mathrm{i}=1}^{\mathrm{n}}\left(\mathrm{R}_{\mathrm{i}}-\overline{\mathrm{R}}\right)^{2}}{\mathrm{n}-1}} ; \\
\left(\mathrm{RUI}_{\mathrm{u}}\right)=\sum_{\lambda=400}^{700} \mathrm{~s}_{\lambda} ; \\
\left(\mathrm{RUI}_{\mathrm{c}}\right)=\sum_{\lambda=400}^{700} \mathrm{~s}_{\lambda} / \overline{\mathrm{R}} ; \\
\mathrm{RUI}=\sum_{\lambda=400}^{700}\left(\mathrm{~s}_{\lambda} / \overline{\mathrm{R}}\right) \mathrm{V}_{\lambda} .
\end{gathered}
$$

Table 4. Relative unlevelness index (RUI) interpretation [41].

\begin{tabular}{cc}
\hline Visual Appearance of Levelness & RUI \\
\hline Excellent (unlevelness not detectable) & $<0.2$ \\
Good (noticeable unlevelness under close examination) & $0.2-0.49$ \\
Poor (apparent unlevelness) & $0.5-1.0$ \\
Bad (conspicuous unlevelness) & $>1.0$ \\
\hline
\end{tabular}

\section{Results}

\subsection{Reflectance Values of the Dyed Samples}

The reflectance curves for a set of wool fabrics dyed with reactive dyes (red, yellow, and blue) in aqueous, octane, and nonane media are presented in Figures 3-5, respectively. The shapes of the reflectance curves for the set of primary dyes should be almost similar (identical), without crossed lines.

As indicated by Figures 3-5, the reflectance curves of fabrics dyed in higher concentrations are presented at the bottom of the graph with lower reflectance values, which indicates that more dyes were absorbed and bonded to fabrics, resulting in darker shades, and vice versa. From the evaluation of reflectance-versus-wavelength graphs, reflectance curves of the set of primary dyes in all concentrations revealed their own color patterns, which were almost identical in shape, and the results obtained were highly consistent.

Moreover, there were curves with a trough profile in the reflectance spectra. These trough profiles became deeper when dye concentration increased, since more light was selectively absorbed by the dye molecules. For instance, as shown in Figure 3a, Figure 4a, Figure 5a, and Figure 6a, the dyed wool fabric appeared "red" since violet-to-yellow light $(400-590 \mathrm{~nm})$ was absorbed, leaving predominantly orange-to-red light $(590-725 \mathrm{~nm})$ in the reflected beam. The increase in spectral reflectance with decreasing dye concentration occurred since the dye on the wool surface scattered light more effectively, resulting in a greater portion of the light beam being reflected back from the dyed wool.

As illustrated in Figures 3-5, reflectance curves of the water-based and reverse-micellar dyed wool maintained identical profiles and exhibited no substantial peak shift in terms of wavelength. This indicates that the reactive dyes remained highly stable in terms of chemical structure after encapsulation in the reverse micelles and complete dyeing process in alkane solvent medium. 
(a)

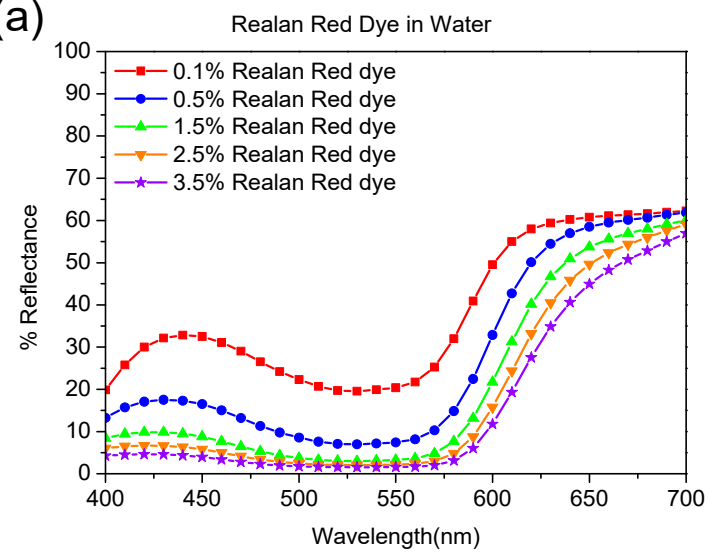

(b)

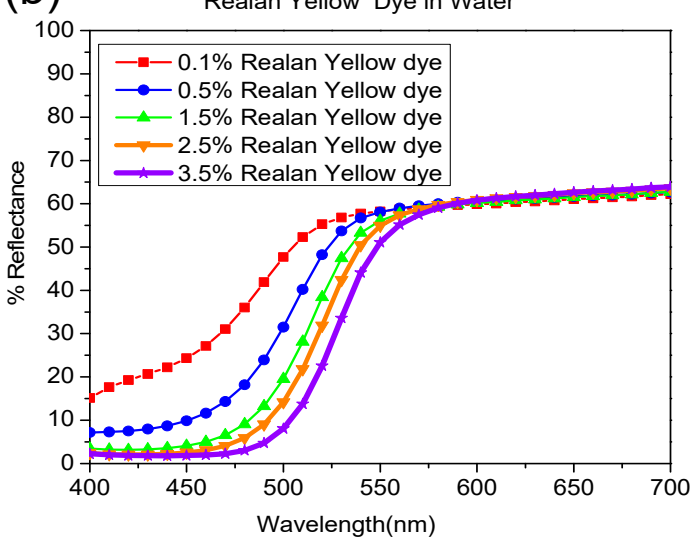

(c) Realan Blue Dye in Water

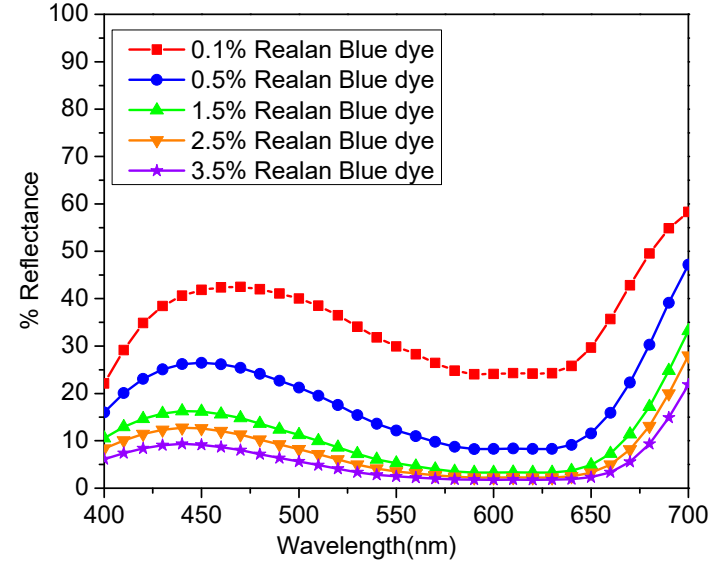

Figure 3. Percentage of reflectance value vs. wavelength (nm) of wool fibers dyed by (a) Realan Reactive Red, (b) Realan Reactive Yellow, and (c) Realan Reactive Blue in water. 

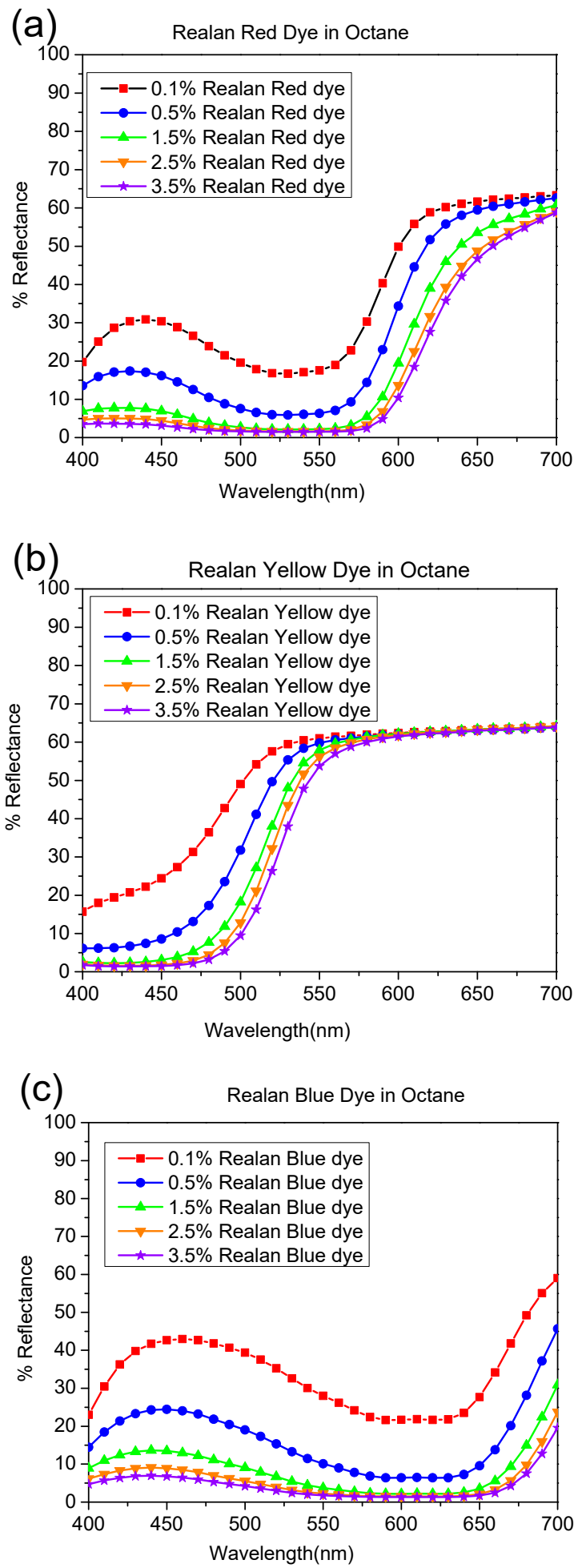

Figure 4. Percentage of reflectance value vs. wavelength (nm) of wool fibers dyed by (a) Realan Reactive Red, (b) Realan Reactive Blue, and (c) Realan Reactive Yellow in octane. 
(a) Realan Red Dye in Nonane

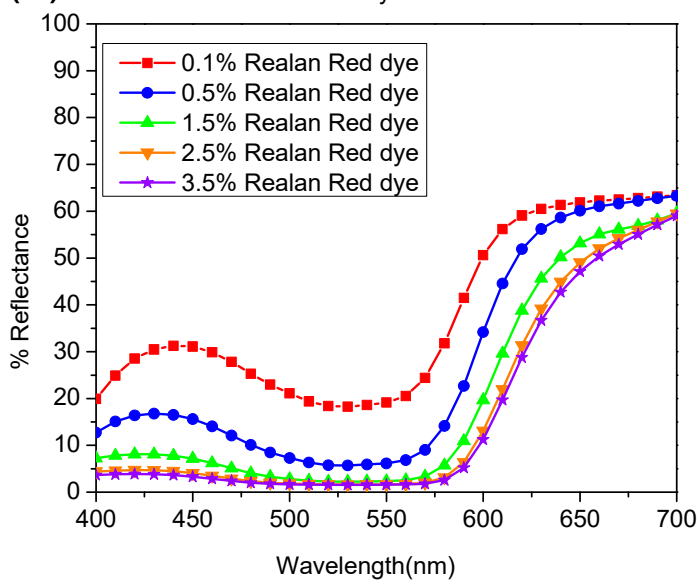

(b) Realan Yellow Dye in Nonane

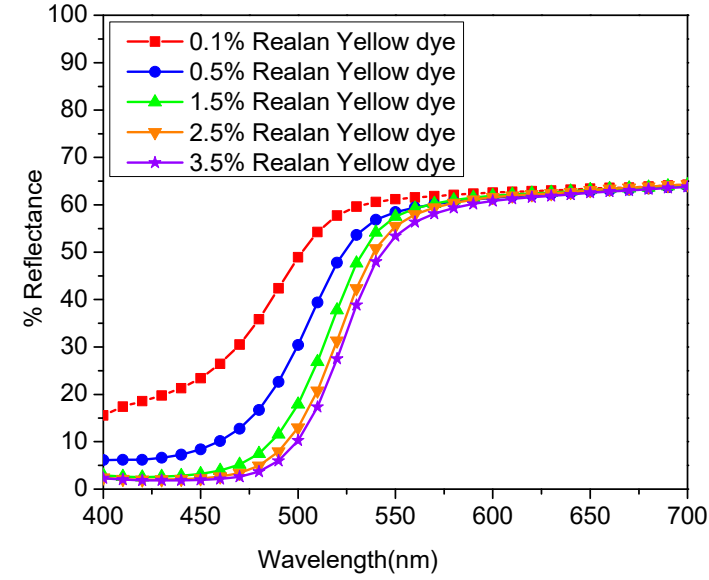

(c)

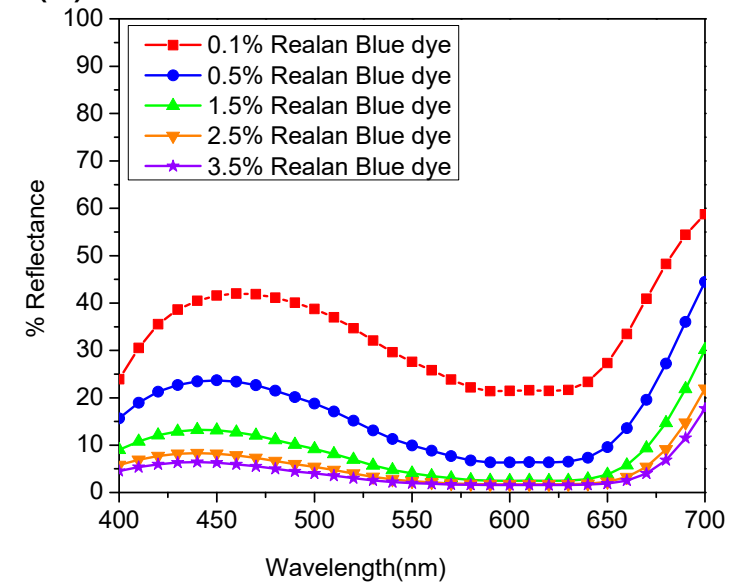

Figure 5. Percentage of reflectance value vs. wavelength (nm) of wool fibers dyed by (a) Realan Reactive Red, (b) Realan Reactive Yellow, and (c) Realan Reactive Blue in nonane.

\subsection{CIE $L^{*} a^{*} b^{*}$ Values}

Table 5 depicts CIE L*a*b* values of wool fabrics dyed in water, octane, and nonane dyeing media. With regards to the red color, wool fabrics dyed using the reverse-micellar dyeing approach in octane and nonane solvent generally had lower $\mathrm{L}^{*}$, and higher $\mathrm{a}^{*}$ and $\mathrm{b}^{*}$ values than those seen using the conventional water-based dyeing approach. The measured CIE L*a*b* values indicate that alkane 
solvent-dyed fabrics in red are darker, redder, and yellower than the conventional water-dyed wool fabrics. Concerning the yellow color, wool fabrics dyed using the reverse-micellar dyeing approach in octane and nonane solvent generally had higher $\mathrm{L}^{*}$, lower $\mathrm{a}^{*}$, and higher $\mathrm{b}^{*}$ values than those seen in the conventional water-based dyeing approach. This means reverse-micellar dyed fabrics in yellow color are lighter, greener, and yellower than the conventional water-dyed wool fabrics. Regarding the blue color, wool woven fabrics dyed in octane and nonane solvent generally had lower $\mathrm{L}^{*}$, higher $\mathrm{a}^{*}$, and lower $\mathrm{b}^{*}$ values than fabrics dyed in water, indicating that the resultant blue color of reverse-micelle dyeing is darker, redder, and bluer than that of the conventional water-based dyeing.

Table 5. The CIE L*a*b* values of dyed wool fabrics in various dyeing media (woven wool fabrics, Realan reactive dye).

\begin{tabular}{cccccccccc}
\hline Solvent & \multicolumn{3}{c}{ Water } & & \multicolumn{3}{c}{ Octane } & \multicolumn{2}{c}{ Nonane } \\
\hline Sample (\%) & $\mathbf{L}^{*}$ & $\mathbf{a}^{*}$ & $\mathbf{b}^{*}$ & $\mathbf{L}^{*}$ & $\mathbf{a}^{*}$ & $\mathbf{b}^{*}$ & $\mathbf{L}^{*}$ & $\mathbf{a}^{*}$ & $\mathbf{b}^{*}$ \\
\hline Red 0.1 & 61.337 & 31.254 & -1.043 & 59.61 & 35.431 & -0.864 & 60.768 & 33.315 & 0.030 \\
Red 0.5 & 47.070 & 45.574 & 1.972 & 46.484 & 48.976 & 1.939 & 46.213 & 49.451 & 2.772 \\
Red 1.5 & 38.009 & 49.965 & 6.687 & 35.454 & 52.490 & 9.185 & 35.691 & 51.966 & 8.551 \\
Red 2.5 & 33.238 & 49.285 & 9.580 & 31.108 & 50.184 & 12.679 & 33.507 & 53.042 & 16.384 \\
Red 3.5 & 29.518 & 47.711 & 12.063 & 28.775 & 48.130 & 15.538 & 28.382 & 47.09 & 15.652 \\
\hline Yellow 0.1 & 79.059 & -5.516 & 35.130 & 80.338 & -5.813 & 36.958 & 80.371 & -6.052 & 38.364 \\
Yellow 0.5 & 76.850 & -2.476 & 61.000 & 77.565 & -2.974 & 65.359 & 76.918 & -1.931 & 65.065 \\
Yellow 1.5 & 74.322 & 3.117 & 78.398 & 74.937 & 3.941 & 84.543 & 74.800 & 4.522 & 84.212 \\
Yellow 2.5 & 73.081 & 7.676 & 86.107 & 73.450 & 7.847 & 91.897 & 73.174 & 8.393 & 88.616 \\
Yellow 3.5 & 70.665 & 14.771 & 90.549 & 71.927 & 11.824 & 93.782 & 71.920 & 11.288 & 90.928 \\
\hline Blue 0.1 & 62.619 & -7.199 & -12.262 & 61.184 & -7.351 & -15.578 & 60.811 & -7.413 & -15.078 \\
Blue 0.5 & 43.906 & -5.392 & -22.837 & 40.789 & -5.312 & -24.752 & 40.515 & -5.380 & -24.244 \\
Blue 1.5 & 30.788 & -2.005 & -25.929 & 26.587 & -1.112 & -26.841 & 27.289 & -1.869 & -24.966 \\
Blue 2.5 & 25.727 & -0.193 & -25.902 & 20.334 & 1.545 & -24.503 & 20.67 & 0.629 & -21.704 \\
Blue 3.5 & 21.181 & 1.884 & -23.685 & 17.507 & 2.150 & -21.859 & 18.066 & 1.871 & -19.012 \\
\hline
\end{tabular}

\subsection{Computer Color-Matching}

\subsubsection{Linearity of the Calibration Curves}

Calibration curves of the red, yellow, and blue batch samples dyed in water and reverse-micellar octane and nonane media are illustrated in Figure 6 . The $\mathrm{K} / \mathrm{S}_{\text {sum }}$ values of red, yellow, and blue samples dyed in the reverse-micellar system were higher than those in water system, indicating that the octane and nonane dyeing system can obtain better color yield than the water-dyeing system.

As illustrated in Figure 6 and Table 6, values of $R^{2}$ of water-dyed fabrics ranged from 0.997 (water blue) to 0.999 (water yellow), whereas $R^{2}$ values of octane-dyed and nonane-dyed fabrics ranged from 0.976 (octane red) to 0.987 (octane blue), and from 0.952 (nonane yellow) to 0.980 (nonane blue), respectively. This indicates that the calibration curves of both reverse-micellar dyed and water-dyed samples are linear-type functions and, thus, appropriate for computer color-matching. 


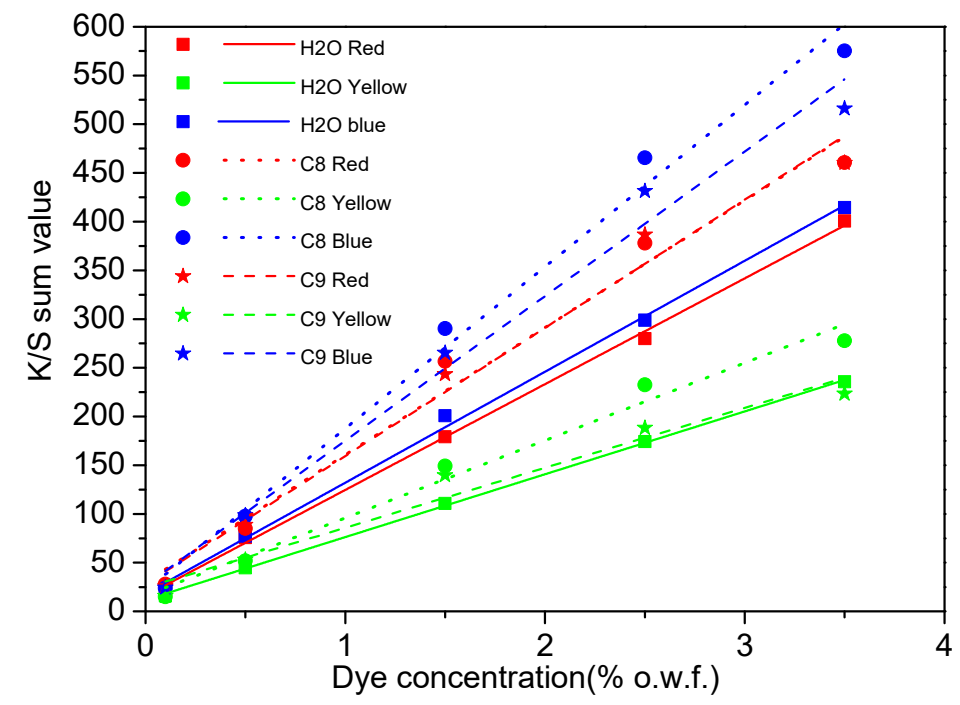

Figure 6. Calibration curves of dyed batch samples in water, octane, and nonane for color-matching.

Table 6. $R^{2}$ values of dyeing in three primary colors based on dyeing method.

\begin{tabular}{cc}
\hline Dyeing Medium & $\boldsymbol{R}^{\mathbf{2}}$ Value \\
\hline Water (red) & 0.998 \\
Water (yellow) & 0.999 \\
Water (blue) & 0.997 \\
\hline Octane (red) & 0.976 \\
Octane (yellow) & 0.977 \\
Octane (blue) & 0.987 \\
\hline Nonane (red) & 0.978 \\
Nonane (yellow) & 0.952 \\
Nonane (blue) & 0.980 \\
\hline
\end{tabular}

\subsubsection{CCM Results}

The color-matching predictions of water-dyed standard wool samples with several color difference formulae are presented in Table 7 . The generated color-matching recipes of Sample 1 were nearly the same (red: 0.108; yellow: 0.114; blue: 0.095) as each other when different formulae were employed. Consistent results were also obtained for color-matching recipes of Sample 2 (red: 0.477; yellow: 0.488; blue: 0.554) and Sample 3 (red: 1.021; yellow: 0.974; blue: 1.081) through different formulations. However, it was observed that variations between color-matching recipes and samples dyed in $1.5 \%$ and $3.0 \%$ concentrations were generally larger than seen in the case of recipes with $0.3 \%$ dye concentration.

Table 7. Color-matching recipes of water-dyed standard wool samples.

\begin{tabular}{ccccc}
\hline \multirow{2}{*}{ Formulae } & \multirow{2}{*}{ Color } & \multicolumn{3}{c}{ Water-Based Wool Dyeing } \\
\cline { 3 - 5 } & & Sample 1 (0.3\%) & Sample 2 (1.5\%) & Sample 3 (3\%) \\
\hline \multirow{3}{*}{ Theoretical } & Red & 0.100 & 0.500 & 1.000 \\
& Yellow & 0.100 & 0.500 & 1.000 \\
& Blue & 0.100 & 0.500 & 1.000 \\
\hline \multirow{2}{*}{ CIE L*a*b* } & Red & 0.108 & 0.477 & 1.021 \\
& Yellow & 0.114 & 0.488 & 0.974 \\
& Blue & 0.095 & 0.554 & 1.081 \\
\hline
\end{tabular}


Table 7. Cont.

\begin{tabular}{ccccc}
\hline \multirow{2}{*}{ Formulae } & Color & \multicolumn{3}{c}{ Water-Based Wool Dyeing } \\
\cline { 3 - 5 } & & Sample 1 (0.3\%) & Sample 2 (1.5\%) & Sample 3 (3\%) \\
\hline \multirow{3}{*}{ CIE L ${ }^{*} \mathbf{u}^{*} \mathrm{~V}^{*}$} & Red & 0.108 & 0.477 & 1.021 \\
& Yellow & 0.114 & 0.488 & 0.974 \\
& Blue & 0.095 & 0.554 & 1.081 \\
\hline \multirow{3}{*}{ ANLAB } & Red & 0.108 & 0.477 & 1.021 \\
& Yellow & 0.114 & 0.488 & 0.974 \\
& Blue & 0.095 & 0.554 & 1.081 \\
\hline \multirow{3}{*}{ Hunter lab } & Red & 0.108 & 0.477 & 1.021 \\
& Yellow & 0.114 & 0.488 & 0.974 \\
& Blue & 0.095 & 0.554 & 1.081 \\
\hline & Red & 0.108 & 0.477 & 1.021 \\
& Yellow & 0.114 & 0.488 & 0.974 \\
& Blue & 0.095 & 0.554 & 1.081 \\
\hline \multirow{2}{*}{ JPC79 } & Red & 0.108 & 0.477 & 1.021 \\
& Yellow & 0.114 & 0.488 & 0.974 \\
& Blue & 0.095 & 0.554 & 1.081 \\
\hline \multirow{2}{*}{ CMC 1.0 } & Red & 0.108 & 0.477 & 1.021 \\
& Yellow & 0.114 & 0.488 & 0.974 \\
& Blue & 0.095 & 0.554 & 1.081 \\
\hline \multirow{2}{*}{ BFD 1.0 } & Red & 0.108 & 0.477 & 1.021 \\
& Yellow & 0.114 & 0.488 & 0.974 \\
& Blue & 0.095 & 0.554 & 1.081 \\
\hline & Red & 0.108 & 0.477 & 1.021 \\
& Yellow & 0.114 & 0.488 & 0.974 \\
& Blue & 0.095 & 0.554 & 1.081 \\
\hline
\end{tabular}

The color-matching recipes of octane-dyed standard wool samples are shown in Table 8. Results were found to be consistent for color-matching predictions of Sample 4 (red: 0.080; yellow: 0.113; blue: 0.105), Sample 5 (red: 0.543; yellow: 0.439; blue: 0.459), and Sample 6 (red: 1.144; yellow: 0.971; blue: 0.959), even though different formulae were used.

Table 8. Color-matching recipes of octane-dyed standard wool samples.

\begin{tabular}{ccccc}
\hline \multirow{2}{*}{ Formulae } & Color & \multicolumn{3}{c}{ Octane Wool Dyeing } \\
\cline { 3 - 5 } & & Sample 4 (0.3\%) & Sample 5 (1.5\%) & Sample 6 (3\%) \\
\hline \multirow{3}{*}{ Theoretical } & Red & 0.100 & 0.500 & 1.000 \\
& Yellow & 0.100 & 0.500 & 1.000 \\
& Blue & 0.100 & 0.500 & 1.000 \\
\hline \multirow{2}{*}{ CIE L*a*b* $^{*}$} & Red & 0.080 & 0.543 & 1.144 \\
& Yellow & 0.113 & 0.439 & 0.971 \\
& Blue & 0.105 & 0.459 & 0.959 \\
\hline \multirow{2}{*}{ CIE L* $\mathbf{u}^{*} \mathrm{v}^{*}$} & Red & 0.080 & 0.543 & 1.144 \\
& Yellow & 0.113 & 0.439 & 0.971 \\
& Blue & 0.105 & 0.459 & 0.959 \\
\hline \multirow{2}{*}{ ANLAB } & Red & 0.080 & 0.543 & 1.144 \\
& Yellow & 0.113 & 0.439 & 0.971 \\
& Blue & 0.105 & 0.459 & 0.959 \\
\hline \multirow{2}{*}{ Hunter lab } & Red & 0.080 & 0.543 & 1.144 \\
& Yellow & 0.113 & 0.439 & 0.971 \\
& Blue & 0.105 & 0.459 & 0.959 \\
\hline
\end{tabular}


Table 8. Cont.

\begin{tabular}{ccccc}
\hline \multirow{2}{*}{ Formulae } & Color & \multicolumn{3}{c}{ Octane Wool Dyeing } \\
\cline { 3 - 5 } & & Sample 4 (0.3\%) & Sample 5 (1.5\%) & Sample 6 (3\%) \\
\hline \multirow{3}{*}{ FMC2 } & Red & 0.080 & 0.543 & 1.144 \\
& Yellow & 0.113 & 0.439 & 0.971 \\
& Blue & 0.105 & 0.459 & 0.959 \\
\hline \multirow{3}{*}{ JPC79 } & Red & 0.080 & 0.543 & 1.144 \\
& Yellow & 0.113 & 0.439 & 0.971 \\
& Blue & 0.105 & 0.459 & 0.959 \\
\hline \multirow{3}{*}{ CMC 1.0 } & Red & 0.080 & 0.543 & 1.144 \\
& Yellow & 0.113 & 0.439 & 0.971 \\
& Blue & 0.105 & 0.459 & 0.959 \\
\hline \multirow{2}{*}{ BFD 1.0 } & Red & 0.080 & 0.543 & 1.144 \\
& Yellow & 0.113 & 0.439 & 0.971 \\
& Blue & 0.105 & 0.459 & 0.959 \\
\hline \multirow{2}{*}{ CIE94 1.0 } & Red & 0.080 & 0.543 & 1.144 \\
& Yellow & 0.113 & 0.439 & 0.971 \\
& Blue & 0.105 & 0.459 & 0.959 \\
\hline
\end{tabular}

The color-matching recipes of nonane-dyed standard wool samples are presented in Table 9. The color-matching predictions of Sample 7, 8, and 9 were (red: 0.086; yellow: 0.081; blue: 0.097), (red: 0.530; yellow: 0.428; blue: 0.464), and (red: 1.107; yellow: 0.960; blue: 0.952), respectively.

Table 9. Color-matching recipes of nonane-dyed standard wool samples.

\begin{tabular}{|c|c|c|c|c|}
\hline \multirow{2}{*}{ Formulae } & \multirow{2}{*}{ Color } & \multicolumn{3}{|c|}{ Nonane Solvent-Assisted Dyeing } \\
\hline & & Sample $7(0.3 \%)$ & Sample $8(1.5 \%)$ & Sample $9(3 \%)$ \\
\hline \multirow{3}{*}{ Theoretical } & Red & 0.100 & 0.500 & 1.000 \\
\hline & Yellow & 0.100 & 0.500 & 1.000 \\
\hline & Blue & 0.100 & 0.500 & 1.000 \\
\hline \multirow{3}{*}{ CIE L $\mathrm{L}^{*} \mathrm{~b}^{*}$} & Red & 0.086 & 0.530 & 1.107 \\
\hline & Yellow & 0.081 & 0.428 & 0.960 \\
\hline & Blue & 0.097 & 0.464 & 0.952 \\
\hline \multirow{3}{*}{ CIE L* $u^{*} v^{*}$} & Red & 0.086 & 0.530 & 1.107 \\
\hline & Yellow & 0.081 & 0.428 & 0.960 \\
\hline & Blue & 0.097 & 0.464 & 0.952 \\
\hline \multirow{3}{*}{ ANLAB } & Red & 0.086 & 0.530 & 1.107 \\
\hline & Yellow & 0.081 & 0.428 & 0.960 \\
\hline & Blue & 0.097 & 0.464 & 0.952 \\
\hline \multirow{3}{*}{ Hunter lab } & Red & 0.086 & 0.530 & 1.107 \\
\hline & Yellow & 0.081 & 0.428 & 0.960 \\
\hline & Blue & 0.097 & 0.464 & 0.952 \\
\hline \multirow{3}{*}{ FMC2 } & Red & 0.086 & 0.530 & 1.107 \\
\hline & Yellow & 0.081 & 0.428 & 0.960 \\
\hline & Blue & 0.097 & 0.464 & 0.952 \\
\hline \multirow{3}{*}{ JPC79 } & Red & 0.086 & 0.530 & 1.107 \\
\hline & Yellow & 0.081 & 0.428 & 0.960 \\
\hline & Blue & 0.097 & 0.464 & 0.952 \\
\hline \multirow{3}{*}{ CMC 1.0} & Red & 0.086 & 0.530 & 1.107 \\
\hline & Yellow & 0.081 & 0.428 & 0.960 \\
\hline & Blue & 0.097 & 0.464 & 0.952 \\
\hline
\end{tabular}


Table 9. Cont

\begin{tabular}{ccccc}
\hline \multirow{2}{*}{ Formulae } & \multirow{2}{*}{ Color } & \multicolumn{3}{c}{ Nonane Solvent-Assisted Dyeing } \\
\cline { 3 - 5 } & & Sample 7 (0.3\%) & Sample 8 (1.5\%) & Sample 9 (3\%) \\
\hline \multirow{3}{*}{ BFD 1.0 } & Red & 0.086 & 0.530 & 1.107 \\
& Yellow & 0.081 & 0.428 & 0.960 \\
& Blue & 0.097 & 0.464 & 0.952 \\
\hline \multirow{2}{*}{ CIE94 1.0 } & Red & 0.086 & 0.530 & 1.107 \\
& Yellow & 0.081 & 0.428 & 0.960 \\
& Blue & 0.097 & 0.464 & 0.952 \\
\hline
\end{tabular}

Table 10 shows the percentage difference (\%) between the theoretical and measured dye concentrations used for standard wool samples dyed by water, octane reverse-micellar, and nonane reverse-micellar approaches using various color difference formulae. Measured values below the expected concentrations were due to the fact that dye molecules were non-uniformly distributed on fabric matrices. Measured values above the predicted concentration were due to the occurrence of various sizes of dye agglomerates, as well as interfering incident light absorption and scattering. In addition, the variation between theoretical and measured concentration was influenced by the linearity of the calibration curves. Generally speaking, a higher linearity of the calibration curves may increase the accuracy and reproducibility of the result, thus leading to a smaller difference between the theoretical and measured concentrations.

Table 10. Percentage (\%) difference of dyed standard wool samples.

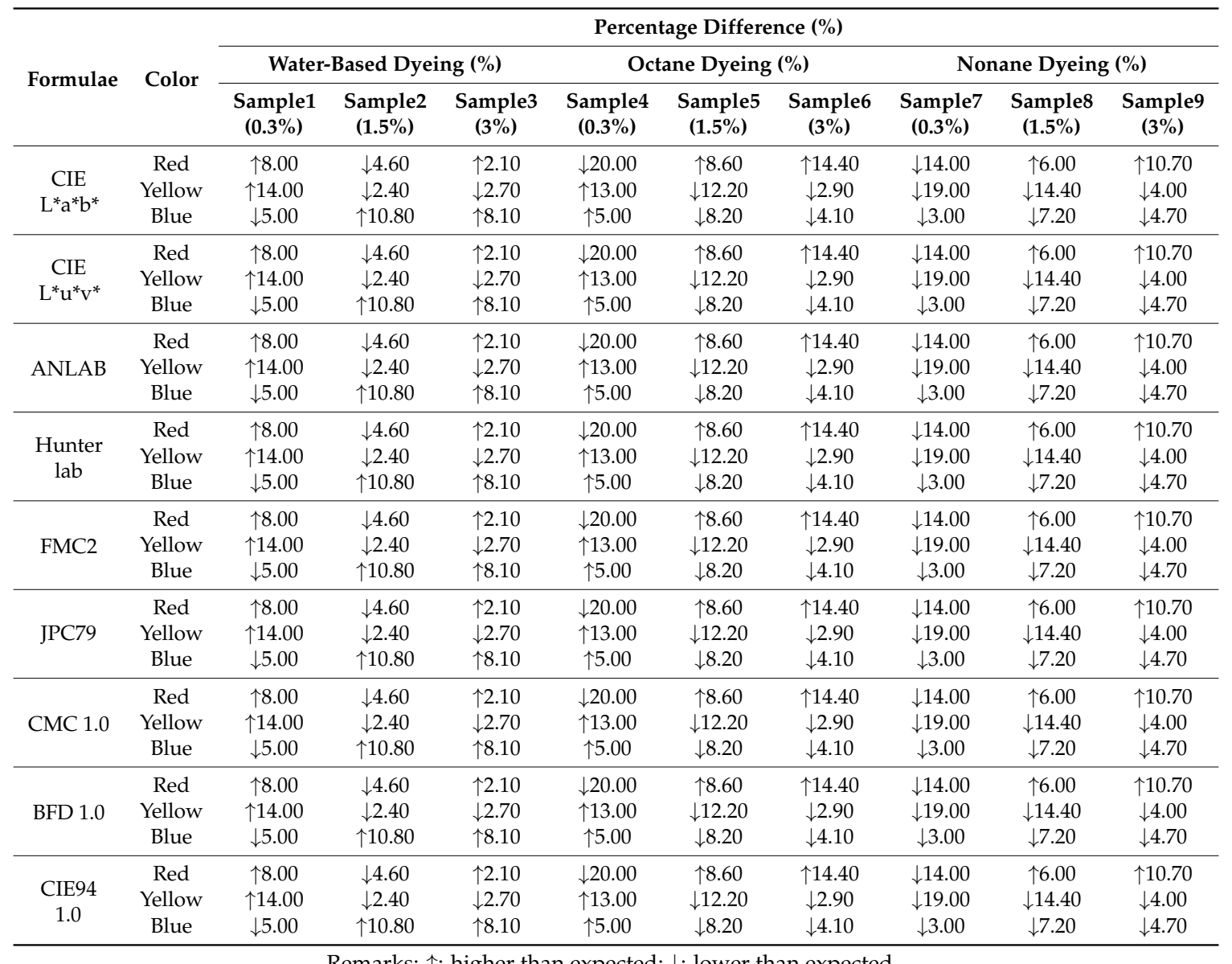

Remarks: $\uparrow:$ higher than expected; $\downarrow$ : lower than expected. 


\subsection{Levelness}

The relative unlevelness indices (RUI) and visual levelness assessments of water-dyed, octane-dyed, and nonane-dyed wool fabrics are illustrated in Table 11. Water-dyed fabrics had values between 0.05 and 0.46 . Octane-dyed and nonane-dyed wool fabrics had values between 0.04 and 0.48 and between 0.04 and 0.43 , respectively. The results indicate that samples dyed by water and solvent methods resulted in good-to-excellent levelness.

Table 11. RUI and visual levelness evaluation of dyed wool samples.

\begin{tabular}{ccccccc}
\hline \multirow{2}{*}{ Sample } & \multicolumn{2}{c}{ Water } & \multicolumn{2}{c}{ Octane } & \multicolumn{2}{c}{ Nonane } \\
\cline { 2 - 7 } & RUI & Visual & RUI & Visual & RUI & Visual \\
\hline Red 0.1\% & 0.40 & Good & 0.45 & Good & 0.26 & Good \\
Red 0.5\% & 0.24 & Good & 0.48 & Good & 0.20 & Good \\
Red 1.5\% & 0.13 & Excellent & 0.20 & Good & 0.43 & Good \\
Red 2.5\% & 0.14 & Excellent & 0.13 & Excellent & 0.14 & Excellent \\
Red 3.5\% & 0.09 & Excellent & 0.44 & Excellent & 0.30 & Good \\
\hline Yellow 0.1\% & 0.09 & Excellent & 0.04 & Excellent & 0.05 & Excellent \\
Yellow 0.5\% & 0.06 & Excellent & 0.05 & Excellent & 0.12 & Excellent \\
Yellow 1.5\% & 0.10 & Excellent & 0.13 & Excellent & 0.04 & Excellent \\
Yellow 2.5\% & 0.09 & Excellent & 0.15 & Excellent & 0.08 & Excellent \\
Yellow 3.5\% & 0.05 & Excellent & 0.13 & Excellent & 0.05 & Excellent \\
\hline Blue 0.1\% & 0.22 & Good & 0.12 & Excellent & 0.31 & Good \\
Blue 0.5\% & 0.16 & Excellent & 0.45 & Good & 0.42 & Good \\
Blue 1.5\% & 0.46 & Good & 0.17 & Excellent & 0.11 & Excellent \\
Blue 2.5\% & 0.08 & Excellent & 0.14 & Excellent & 0.34 & Good \\
Blue 3.5\% & 0.08 & Excellent & 0.07 & Excellent & 0.08 & Excellent \\
\hline Mixture 0.3\% & 0.19 & Excellent & 0.28 & Excellent & 0.20 & Good \\
Mixture 1.5\% & 0.34 & Good & 0.22 & Excellent & 0.29 & Good \\
Mixture 3.0\% & 0.08 & Excellent & 0.14 & Excellent & 0.18 & Excellent \\
\hline
\end{tabular}

\section{Conclusions}

Computer color-matching and the levelness of octane and nonane reverse-micellar dyed wool fabrics were investigated using PEG-based non-ionic surfactants, and the results were found comparable to those found for the conventional water-based dyeing system. No chromatic change was observed from the measured reflectance values. The calibration curves were almost linear in reflectance functions for both dyeing systems. The linearity of the water-dyed calibration curves was slightly higher than that for the reverse-micellar dyed curves. However, the color yield in terms of $K / S_{\text {sum }}$ values for solvent-dyed samples was found to be higher than that for the water-dyed samples at each calibrated dye concentration. CCM was conducted using various spectral matching methods, and the results revealed that the CCM-predicted concentrations closely matched with the theoretical concentrations for both methods. This indicates that the octane and nonane dyeing of wool can achieve color-matching comparable to the water dyeing of wool. The RUI results implied that both water-dyed and solvent-dyed wool samples can subjectively and objectively achieve good-to-excellent levelness performance.

Author Contributions: C.-W.K. and Y.W. designed the experiments; Y.W., Y.-I.T., and C.-h.L. performed the experiments and analyzed the data; Y.W. and Y.-l.T. wrote the paper; C.-h.L. and C.-W.K. revised the paper. All authors discussed the results and improved the final draft of the paper.

Funding: This research was funded by The Hong Kong Polytechnic University, grant numbers 4-ZZGK and G-UADU. The APC was funded by G-UADU.

Acknowledgments: The authors are thankful to The Hong Kong Polytechnic University for providing financial support.

Conflicts of Interest: The authors declare no conflicts of interest. 


\section{References}

1. Long, J.J.; Cui, C.-L.; Wang, L.; Xu, H.M.; Yu, Z.J.; Bi, X.P. Effect of treatment pressure on wool fiber in supercritical carbon dioxide fluid. J. Clean. Prod. 2013, 43, 52-58. [CrossRef]

2. Shen, J.; Gao, P.; Ma, H. The effect of tris(2-carboxyethyl)phosphine on the dyeing of wool fabrics with natural dyes. Dyes Pigment. 2014, 108, 70-75. [CrossRef]

3. Kan, C.W.; Yuen, C.W.M.; Hung, O.N. Improving the pilling property of knitted wool fabric with atmospheric pressure plasma treatment. Surf. Coat. Technol. 2013, 228 (Suppl. 1), S588-S592. [CrossRef]

4. Panda, P.K.; Rastogi, D.; Jassal, M.; Agrawal, A.K. Effect of atmospheric pressure helium plasma on felting and low temperature dyeing of wool. J. Appl. Polym. Sci. 2012, 124, 4289-4297. [CrossRef]

5. Christie, R.M. The Chemistry of Colour Application; Blackwell Science: Oxford, UK; Malden, MA, USA, 2000.

6. Broadbent, A.D. Basic Principles of Textile Coloration (Textile Coloration); Society of Dyers and Colorists: Bradford, UK, 2001.

7. Chen, L.; Wang, B.; Chen, J.; Ruan, X.; Yang, Y. Characterization of dimethyl sulfoxide-treated wool and enhancement of reactive wool dyeing in non-aqueous medium. Text. Res. J. 2016, 86, 533-542. [CrossRef]

8. Cho, H.J.; Lewis, D.M.; Jia, B.H. Improved reactive dyeing of wool with novel trifunctional reactive dyes. Color. Technol. 2007, 123, 86-95. [CrossRef]

9. Sadeghi-Kiakhani, M.; Safapour, S. Eco-friendly dyeing of treated wool fabrics with reactive dyes using chitosanpoly(propylene imine) dendreimer hybrid. Clean Technol. Environ. Policy 2015, 17, 1019-1027. [CrossRef]

10. Jocić, D.; Julià, M.R.; Erra, P. Application of a chitosan/nonionic surfactant mixture to wool assessed by dyeing with a reactive dye. J. Soc. Dyers Colour. 1997, 113, 25-31. [CrossRef]

11. Yen, M.S. Application of chitosan/nonionic surfactant mixture in reactive dyes for dyeing wool fabrics. J. Appl. Polym. Sci. 2001, 80, 2859-2864. [CrossRef]

12. Zhao, X.; He, J.X.; Zhan, Y.Z. Research in the cold pad-batch dyeing process for wool pretreated by hydrogen peroxide. Color. Technol. 2009, 125, 172-177. [CrossRef]

13. Naebe, M.; Cookson, P.G.; Rippon, J.A.; Wang, X.G. Effects of leveling agent on the uptake of reactive dyes by untreated and plasma-treated wool. Text. Res. J. 2010, 80, 611-622. [CrossRef]

14. Zhang, H.; Yan, H.; Mao, N. Functional modification with $\mathrm{TiO}_{2}$ nanoparticles and simultaneously dyeing of wool fibers in a one-pot hydrothermal process. Ind. Eng. Chem. Res. 2014, 53, 2030-2041. [CrossRef]

15. Xue, Z. Study of dyeing properties of wool fabrics treated with microwave. J. Text. Inst. 2016, 107, $258-263$. [CrossRef]

16. Mendhe, P.; Arolkar, G.; Shukla, S.; Deshmukh, R. Low-temperature plasma processing for the enhancement of surface properties and dyeability of wool fabric. J. Appl. Sci. 2016, 133, 43097. [CrossRef]

17. Zhang, Y.Q.; Wei, X.C.; Long, J.J. Ecofriendly synthesis and application of special disperse reactive dyes in waterless coloration of wool with supercritical carbon dioxide. J. Clean. Prod. 2016, 133, 746-756. [CrossRef]

18. Gomes, J.I.N.R.; Genovez, M.C.; Hrdina, R. Controlling Exhaustion of Reactive Dyes on Wool by Microencapsulation with Liposomes. Text. Res. J. 1997, 67, 537-541. [CrossRef]

19. El-Zawahry, M.M.; El-Shami, S.; El-Mallah, M.H. Optimizing a wool dyeing process with reactive dye by liposome microencapsulation. Dyes Pigment. 2007, 74, 684-691. [CrossRef]

20. Moussa, A.; El Ghali, A.; Ellouzi, S.; Sakli, F. Color and fastness study of wool dyeing in multiple reuse dye baths using acid and reactive dyestuffs in laboratory scale. J. Text. Inst. 2013, 104, 260-269. [CrossRef]

21. Broadbent, P.J.; Carr, C.M.; Rigout, M.; Kistamah, N.; Choolun, J.; Radhakeesoonb, C.L.; Uddinc, M.A. Investigation into the dyeing of wool with Lanasol and Remazol reactive dyes in seawater. Color. Technol. 2018, 134, 156-161. [CrossRef]

22. Bhavsar, P.S.; Zoccola, M.; Patrucco, A.; Montarsolo, A.; Mossotti, R.; Giansetti, M.; Rovero, G.; Maier, S.S.; Muresan, A.; Tonin, C. Superheated water hydrolyzed keratin: A new application as a foaming agent in foam dyeing of cotton and wool fabrics. ACS Sustain. Chem. Eng. 2017, 5, 9150-9159. [CrossRef]

23. McNeil, S.J.; McCall, R.A. Ultrasound for wool dyeing and finishing. Ultrason. Sonochem. 2011, 18, 401-406. [CrossRef]

24. Sanislav, A.; Fogorasi, M.; Stanescu, M.D.; Muntean, S.; Dochia, M. Ultrasound effect on dyeing wool fibers with two anthraquinone dyes. Fibers Polym. 2015, 16, 62-66. [CrossRef] 
25. Hassan, M.M.; Bhagvandas, M. Sustainable ultrasound-assisted ultralow liquor ratio dyeing of wool textiles with an acid dye. ACS Sustain. Chem. Eng. 2017, 5, 973-981. [CrossRef]

26. Church, J.S.; Davie, A.S.; Scammells, P.J.; Tucker, D.J. Lanasol dyes and wool fibres. Part I: Model studies on the mechanism of dye fixation in a mixed solvent system. Dyes Pigment. 1998, 39, 291-312. [CrossRef]

27. Sawada, K.; Takagi, T.; Jun, J.H.; Ueda, M.; Lewis, D.M. Dyeing natural fibres in supercritical carbon dioxide using a nonionic surfactant reverse micellar system. Color. Technol. 2002, 118, 233-237. [CrossRef]

28. Sawada, K.; Jun, J.H.; Ueda, M. Dyeing of natural fibres from perfluoro-polyether reverse micelles in supercritical carbon dioxide. Color. Technol. 2003, 119, 336-340. [CrossRef]

29. Sawada, K.; Ueda, M. Dyeing of protein fiber in a reverse micellar system. Dyes Pigment. 2003, 58, 99-103. [CrossRef]

30. Schmidt, A.; Bach, E.; Schollmeyer, E. The dyeing of natural fibres with reactive disperse dyes in supercritical carbon dioxide. Dyes Pigment. 2003, 56, 27-35. [CrossRef]

31. Van der Kraan, M.; Fernandez Cid, M.V.; Woerlee, G.F.; Veugelers, W.J.T.; Witkamp, G.J. Dyeing of natural and synthetic textiles in supercritical carbon dioxide with disperse reactive dyes. J. Supercrit. Fluids 2007, 40, 470-476. [CrossRef]

32. Zheng, H.; Xu, Y.; Zhang, J.; Xiong, X.; Yan, J.; Zheng, L. An ecofriendly dyeing of wool with supercritical carbon dioxide fluid. J. Clean. Prod. 2017, 143, 269-277. [CrossRef]

33. Pileni, M. Reverse micelles as microreactors. J. Phys. Chem. 1993, 97, 6961-6973. [CrossRef]

34. Peyravi, A.; Gashti, M.P.; Hosseini, S.H. Chemical grafting of disperse dyes onto polyacrylonitrile: A novel method for coloration of fibers. Fibers Polym. 2014, 15, 2307-2312. [CrossRef]

35. Gashti, M.P. New insight into compressive shrinkage finishing in a garment company: The effects on physical, mechanical and colorimetric properties of cotton woven fabrics. Fibers Polym. 2016, 17, 130-135. [CrossRef]

36. Ebrahimia, I.; Gashti, M.P.; Sarafpour, M. Photocatalytic discoloration of denim using advanced oxidation process with $\mathrm{H}_{2} \mathrm{O}_{2}$ /UV. J. Photochem. Photobiol. A Chem. 2018, 360, 278-288. [CrossRef]

37. Ebrahimia, I.; Gashti, M.P. Extraction of polyphenolic dyes from henna, pomegranate rind, and Pterocarya fraxinifolia for nylon 6 dyeing. Color. Technol. 2016, 132, 162-176. [CrossRef]

38. Kiumarsi, A.; Gashti, M.P.; Salehi, P.; Dayeni, M. Extraction of dyes from Delphinium Zalil flowers and dyeing silk yarns. J. Text. Inst. 2017, 108, 66-70. [CrossRef]

39. Wang, Y.M.; Lee, C.H.; Tang, A.Y.L.; Kan, C.W. Dyeing cotton in alkane solvent using polyethylene glycol-based reverse micelle as reactive dye carrier. Cellulose 2016, 23, 965-980. [CrossRef]

40. Tang, A.Y.L.; Lee, C.H.; Wang, Y.M.; Kan, C.W. Octane-assisted reverse micellar dyeing of cotton with reactive dyes. Polymers 2017, 9, 678. [CrossRef]

41. Tang, A.Y.L.; Wang, Y.M.; Lee, C.H.; Kan, C.W. Computer color matching and levelness of PEG-based reverse micellar decamethyl cyclopentasiloxane (D5) solvent-assisted reactive dyeing on cotton fiber. Appl. Sci. 2017, 7, 682. [CrossRef]

42. Tang, A.Y.L.; Lee, C.H.; Wang, Y.M.; Kan, C.W. Dyeing properties of cotton with reactive dye in nonane nonaqueous reverse micelle system. ACS Omega 2018, 3, 2812-2819. [CrossRef]

43. Tang, A.Y.L.; Lee, C.H.; Wang, Y.M.; Kan, C.W. Effect of hydrophilic-lipophilic balance (HLB) values of PEG-based non-ionic surfactant on reverse micellar dyeing of cotton fibre with reactive dyes in non-aqueous medium. Fibers Polym. 2018, 19, 894-904. [CrossRef]

44. Tang, A.Y.L.; Wang, Y.M.; Lee, C.H.; Kan, C.W. Comparison of computer colour matching of water-based and solvent-based reverse micellar dyeing of cotton fibre. Color. Technol. 2018, 134, 258-265. [CrossRef]

45. Xin, J.H. Controlling Colourant Formulation in Total Colour Management in Textiles; Woodhead Publishing: Sawston, UK, 2006; pp. 136-159.

46. Gulrajani, M. Colour Measurement: Principles, Advances and Industrial Applications; Woodhead Publishing: Cambridge, UK, 2010.

47. Chong, C.; Li, S.; Yeung, K. An objective method for the assessment of levelness of dyed materials. J. Soc. Dyers Colour. 1992, 108, 528-530. [CrossRef]

(C) 2019 by the authors. Licensee MDPI, Basel, Switzerland. This article is an open access article distributed under the terms and conditions of the Creative Commons Attribution (CC BY) license (http:/ / creativecommons.org/licenses/by/4.0/). 